\title{
The Equine Faecal Microbiota Undergoes Step-wise Compositional Changes in Accordance With Increasing Levels of Domestication
}

Katie Bull ( $\square$ katie.bull@bristol.ac.uk)

University of Bristol https://orcid.org/0000-0002-6681-2162

Gareth Davies

University of Bristol

Timothy Patrick Jenkins

Technical University of Denmark: Danmarks Tekniske Universitet

Laura Elizabeth Peachey

University of Bristol

Research Article

Keywords: Horse, 16S rRNA sequencing, Microbiome, Diet, Domestication, Helminth

Posted Date: February 8th, 2021

DOI: https://doi.org/10.21203/rs.3.rs-164863/v1

License: @ (1) This work is licensed under a Creative Commons Attribution 4.0 International License. Read Full License 


\section{Abstract}

\section{Background}

Changes to the gut microbiota are associated with an increased incidence of disease in many species. This is particularly important during the process of domestication, where captive animals commonly suffer from gastrointestinal (GI) pathology. Horses are a prime example of a species which suffers from a high incidence of (often life-threatening) GI diseases in domesticated environments. We aimed to indentify the gut microbial changes which occur due to domestication in horses by profiling the faecal microbiota of adult female Exmoor ponies under three management conditions, representing increasing levels of domestication.

\section{Methods}

Faecal samples were collected from 29 adult female Exmoor ponies in the South West of the UK; ponies were categorised as Feral $(n=10)$, Semi-Feral $(n=10)$ and Domesticated $(n=9)$, based on their management conditions; thus controlling for age, gender and random effects between groups. Diet and medication were recorded and faecal samples taken to assess parasite infection. Faecal microbial composition was profiled via high-throughput sequencing of the bacterial 16S rRNA gene.

\section{Results}

Downstream biostatistical analysis indicated profound step-wise changes in global microbial community structure in the transition from Feral to Semi-Feral to Domesticated groups. A relatively high abundance of members of the phylum Proteobacteria and Tenericutes were associated with the Domesticated group; and higher levels of Methanobacteria were seen in the Feral group. The Semi-Feral group frequently had intermediate levels of these taxa; however, they also exhibited the greatest 'within group' variation in bacterial diversity and parasites burdens. Functional predictions revealed increased amino acid and lipid metabolism in the Domesticated group and increased energy metabolism in the Feral group; supporting a hypothesis that differences in diet was the key driver of gut microbial composition.

\section{Conclusions}

If assumed the Feral population has a more natural gut microbial phenotype, akin to that with which horses have evolved, these data can potentially be used to provide microbial signitures of balanced gut homeostasis in horses; which, in turn, will aid prevention of GI disease in domesticated horses.

\section{Background}

Humans have been domesticating animals on this planet for thousands of years, with the first cases in dogs estimated to be around 16,000 years ago [1]. This process is associated with changes to an animal's natural environment, diet, breeding and behaviour $[2,3,4,5]$, often with a negative impact on animal health $[6,7,8,9]$. In particular, domesticated and/or captive animals commonly suffer from gastrointestinal (GI) pathology $[10,11,12]$, indicating that domestication can result in changes to the $\mathrm{GI}$ microenvironment which compromise animal health.

Horses constitute a prime example of a domesticated species which suffer from a high incidence of (often life-threatening) GI disease $[13,14,15,16]$. Unsurprisingly, the diet and feeding methods of domesticated horses often do not mimic those of wild horses and, furthermore, changes in feeding, environment and management often precede episodes of $\mathrm{GI}$ disease $[17,18,19]$. Data on the developing microbiota in foals show that the transition to an adult gut microbiome involves a rapid increase in microbial diversity and increasing proportions of fibre digesting taxa belonging to Bacteroidetes and Fibrobacter Phyla [20, 21]. As horses are hind-gut fermenters, this process is key to the ability to utilise dietary fibre and optimise gut health. Notably, alterations to microbial communities of the equine gut have been intrinsically linked to GI diseases of domestication such as colic and colitis [18,22,23]; furthermore, obesity and metabolic disease in native pony breeds is associated with alterations to the equine $\mathrm{GI}$ microbiota $[24,25,26]$. To understand how we can better manage domesticated horses and prevent $\mathrm{GI}$ and metabolic disease, it is important that we understand how, and why, the domesticated equine microbiome differs from it's natural state.

A handful of studies have investigated the impact of domestication on the GI microbiota of equids, with varying results $[27,28,29,5,30]$. For example, one study found that domestication was associated with reduced microbial alpha diversity [4], whilst 
others showed no effect $[31,32,33$,$] . There is little agreement in taxonomic changes due to domestication between these studies; and$ whilst the data are a useful indication of the variation that we can expect to see in the gut microbiome within the genus Equus, and in different environments, it is difficult to draw general conclusions, as the specific impact of domestication was confounded by the presence of many other variables (e.g. genetics, sex and age) which are known to influence the microbiota $[34,35,36,37,38,39]$. Furthermore, most studies to date include only two study groups, one of which is wild/feral, and the other domesticated $[4,27,29,30,32,40]$; and you would expect to see differences between any two groups of horses which are managed separately, regardless of their level of domestication.

Therefore, in this study we investigated the impact of domestication on the equine microbiome by characterising the faecal microbiota of horses under three different types of management - representing step-wise increases in the level of domestication. To make this process more rigorous, we matched each sub-population for breed, sex, approximate age and time of sampling, whilst recording differences in diet, helminth parasite infections and recent/historical drug treatments.

\section{Results}

\section{Microbiota Profiling}

Freshly voided faecal samples from 29 adult female Exmoor ponies were collected in May 2019 from three populations categorised at different levels of domestication. A Feral group $(n=10)$, born wild, with no human intervention and grazed on 344 acres of rough moorland dominated by purple moor grass, brown, bent and deer grass, bracken, heather and other native plant species. A Semi-Feral group $(n=10)$ with some human interference which were born wild, grazed on a combination of managed moorland and rye grass mix pasture of approximately 60 acres. The Semi-Feral group were administered a yearly anthelmintic in winter as well as supplementation with hay during this time. This group was minimally handled for health monitoring, anthelmintic administration and hoof trimming. The remaining 9 were from a highly domesticated group, which were born in captivity, regularly handled, given anthelmintics 3 times a year, grazed on a ryegrass pasture and fed hay, concentrate and stabled at night during the autumn and winter. At the time of sampling none of the animals in the study were stabled, or receiving supplementary rations on a regular basis; hence the main dietary difference between them was the level of access to ryegrass versus rough moorland grazing. Furthermore, none of the animals in the study had been treated with an anthelmintic, or any other medication, in the last 8 weeks. DNA was extracted from each faecal sample individually followed by identification of microbial community composition by amplicon sequencing of the V3-V4 hypervariable region of the bacterial 16S rRNA gene.

From the 29 faecal samples 1946910 (range per sample 30244-275624) raw paired-end reads were generated. Following primer trimming, joining of paired-end reads, filtering of low-quality sequences, denoising and chimera removal, a total of 844,229 (range per sample 10,077-128,378) high-quality sequences were retained for further bioinformatics analyses. The rarefaction curves generated following in silico subtraction of low-quality and contaminant sequences indicated that the majority of samples were sequenced at adequate read depth, thus allowing us to undertake further analyses (Additional File 1). Raw data and metadata was uploaded to the European Nucleotide Archive (ENA) (accession number PRJEB39336). Taxonomic assignment was performed in QIIME2, using a classifier trained for $99 \%$ accuracy on the SILVA database [41]. The bacterial phyla Firmicutes (36.71\%) and Bacteroidetes (30.99\%) were predominant in all samples, followed by the phyla Kiritimatiellaeota (9.58\%), Spirochaetes (4.56\%), Verrucomicrobia (3.93\%), Fibrobacteres (3.60\%), Planctomycetes (2.30\%), Actinobacteria (2.11\%) Euryarchaeota (2.05\%), Cyanobacteria (1.37\%), Proteobacteria $(0.85 \%)$, Lentisphaerae $(0.57 \%)$, Synergistetes $(0.38 \%)$, Armatimonadetes $(0.25 \%)$, Patescibacteria $(0.25 \%)$, Tenericutes $(0.23 \%)$, WPS-2 (0.09\%), Elusimicrobia $(0.04 \%)$, Chloroflexi $(0.02 \%)$, Epsilonbacteraeota $(0.004 \%)$, Chlamydiae $(0.002 \%)$, Acidobacteria $(0.0005 \%)$ and Dependentiae $(0.0002 \%)$ (Figure 1$) ; 0.09 \%$ of OTUs could not be assigned to any bacterial group.

\section{Clear step-wise differences in beta diversity were observed with increasing levels of domestication}

Multivariate analysis of beta diversity between groups was performed on a weighted unifrac distance matrix using unsupervised Principle Coordinate Analysis (PCoA) and supervised Canonical Correspondence Analysis (CCA). PCoA demonstrated clear clustering by population with the greatest difference seen between Domesticated and Feral groups with the Semi-Feral group spanning between the two (Figure 2a). Canonical Correspondence Analysis (CCA) showed a highly significant difference between the three groups $(P=0.001, \mathrm{~F}=4.59)$ (Figure 2b). 
There were no significant differences in alpha diversity between farms (evenness $P=0.35$; Shannon $P=0.2$; Richness $P=0.33$ ). However, greater inter-individual variation in alpha diversity was seen between animals in the Semi-Feral group (see Additional File 2)

\section{Many bacterial taxa showed clear step-wise differences in relative abundance according to domestication level}

Differences in the abundance of specific bacterial taxa between the groups was evaluated using LEfSe (Linear Discriminant Analysis Effect Size) analysis [42] (Table 1 and Additional Table 1). Examples of taxa which altered most significantly between groups are represented graphically in ANOVA plots (Figure 3). Many observed differences step-wise alterations between groups from Domesticated, to Semi-Feral, to Feral; with Semi-Feral representing an intermediate between the two other groups. The highest disparity (with regards to number of signficant differences observed) between study groups was seen at the family level, and these differences were represented visually in a network analysis for clarity (Figure 4). As for the PCoA, the network analysis showed clear clustering by population, with the least correlation between taxa in the Domesticated and Feral group, and the Semi-Feral group showing a profile spanning that of the other two groups (Figure 4). In summary, the taxa Kirimatiellaeota (Lowest significant taxonomic level (LTL): Kiritimatiellae), Tenericutes (LTL: Anaeroplasma, Mycoplasma), Alphaproteobacteria (LTL: Rhizobales), Deltproteobacteria (LTL: Desulfovibrio), Synergistes (LTL: Pyramidobacter), Actinomycetales (LTL: Mycobacterium), Negativicutes (LTL: Acidaminococcaceae), Optituales and Lentispherae (LRL: Victivallaceae) showed step-wise reductions in relative abundance from Domesticated > Semi Feral > Feral (Figure 3). Whereas the taxa Chlorflexi (LTL: Anaerolineaceae), Actinobacteria (LTL: Eggerthellaceae, Atopobiaceae, Coriobacteriaceae), Euryarchaeota (LTL: Methanobrevibacter) and Clostridiales (LTL: Lachnospiracaea, Shuttlesworthia) showed step-wise reductions in relative abundance from Feral $>$ Semi Feral $>$ Domesticated (Figure 3). The abundance of taxa in the Semi-Feral group often represented an intermediate state between domesticated and feral groups, as seen in the network analysis. However, there were some taxa which were differentially abundant in this group. Increases in relative abundance were observed for Actinobacteria (LTL: Micrococcales (Arthrobacter) and Propionibacteriales (LTL: Aeromicrobium), Gammaproteobacteria (LTL: Pseudomonales and Succinovibrionaceae), Bacillales (LTL: Bacillus), Selenomondales (LTL: Anaerovibrio), Prevotellaceae UCG001, Saccharomonas (synonyms - Zymomonas, Pseudomonas), Methanocorpusculum and Clostridium butyricum (Additional Table 1).

\section{Differences in Faecal egg counts between populations, and correlation between FEC and individual bacterial taxa}

The FEC profiles between the groups were compared by one-way ANOVA using R studio [43], and were signficantly different $(P=0.005)$, with domesticated having lower FEC on average than the Feral and Semi-Feral groups; there was more inter-individual variation in FEC in the Semi-Feral group (Additional Table 2; Supplementary Fig 4). Association of individual bacterial taxa with faecal egg count (FEC) was assessed using linear regression analysis (Figure 5). For ease of comparison, the results of regression analysis are summarised alongside LEfSe results in Table 1. Bacterial taxa most significantly correlated with FEC are shown graphically in Figure 5. Of the taxa which were increased in the Domesticated group; Kirimatiellaeota, Lentispherae, Alphaproteobacteria and Tenericutes were also negatively correlated with FEC. Of those taxa increased in the Feral group Actinobacteria (Eggerthellaceae), and Lachnospiraceae (Shuttlesworthia) were also positively correlated with FEC. Of those taxa increased in the Semi-feral group, Micrococcales, Proponibacteriales and pseudomonales, and Prevotellaceae UCG001 were also positively correlated with FEC.

\section{Predicted functional analysis from $16 \mathrm{~S}$ sequencing data}

Phylogenetic Investigation of Communities by Reconstruction of Unobserved States (PICRUST) with KEGG Orthology (KOs) classification was used on the data to predict the functional implications of differences between microbial community structure between Domesticated, Semi-feral and Feral groups [44]. Network analysis with Pearson's Correlation was used to demonstrate functional differences between the groups; the clearest differences between groups was seen at KEGG level 2 (Figure 6). As seen with beta diversity and taxonomic analyses, functional pathways in the Feral and Domesticated were poorly correlated with each other, whereas pathways upregulated in the Semi-feral group spanned between them. LEfSe analysis of predicted functional data supported the network analysis (Additional File 3); glycan, amino acid, lipid, polyketides and xenobiotics metabolism were increased in the Domesticated group; carbohydrate metabolism, cancers, neurogenerative diseases, excretory system, immune system diseases and metabolic diseases were increased in the Semi-feral group; and energy metabolism, transcription, membrane transporters and genetic information processing were increased in the Domesticated group. 


\section{Discussion}

In this study we have reported a clear difference in faecal microbial composition and predicted function between adult horses of the same breed and gender, but different levels of domestication; ranging from no human intervention to high human intervention (i.e., Feral - Semi-feral - Domesticated). The overall structure of the microbiome in the study participants was similar to that previously described for horses, with the most abundant phyla being Firmicutes and Bacteroidetes $[45,21,46,47,48,22,25]$. There were clear differences in global composition between the groups according to unsupervised beta diversity analysis. This was supported by supervised multivariate analysis using CCA, in which the differences between the three groups were significant $(p=0.001)$. Clustering of individuals according to PCoA (Fig $2 \mathrm{~b}$ ) showed that the greatest difference in microbial beta diversity was between Domesticated and Feral groups, and the Semi-feral animals spanned between them, indicating step-wise differences in the composition of the faecal microbiota in response to increasing levels of domestication. The predicted functional changes mirrored those in the micorbiome data, with a network analysis revealing the least correlation between the Feral and Domesticated groups. To our knowledge, this is the first time a step-wise response to domestication level has been described in the equine GI microbiota.

Based on previous studies of the equine microbiome [49], and given that all animals were clinically healthy at the time of sampling, the differences in management between groups which were likely to be responsible for the observed differences were diet $[31,19$, $50,51,17,52]$, drug use $[53,48,54,57]$, level of GI parasites [48,54,55] and, potentially, handling stress [56]. We attempted to dissect these factors by recording the dietary differences, drug use and GI helminths burden (by proxy of FEC) in each group at the time of sampling. It being spring, the main difference in diet between groups was the level of access to managed ryegrass pasture versus rough moorland grazing; although the Semi-Feral and Domesticated groups had also received supplementary hay and concentrate (in the case of the latter) over the winter. None of the animals in the study had been treated with an antibiotic, nor anthelmintic in the last 8 weeks, and previous studies have shown that anthelmintic use alone has small and transient effects on the GI microbiota $[48,54,57,53]$. Therefore, we assumed that there were no direct effects of anti-infective drugs at the time of sampling. However, evidently the different parasite treatment protocols have led to different FEC profiles between groups.

Strongyle FECs were significantly lower in the Domesticated group (Additional File 4), which is expected as these animals were tested and treated more regularly for these parasites. The average FEC was similar between the Feral and Semi-feral group, however there was much greater variation in parasite burden between animals in the Semi-Feral group (Additional Table 2; Additional File 4). Of note, the ponies in this group were wormed only once per year, and they were kept in a relatively restricted area which would allow for the build-up of parasites on the pasture. Therefore, it is likely that these animals were exposed to high helminth infection intensity and, consequently, parasite burdens would fluctuate widely between treatments. Over the course of the year, the diet of the Semiferal herd would also be expected to fluctuate more than the other two groups as they were grazed on different pasture types and had sporadic supplementation with hay. Both dietary changes and acute helminth infection have been shown to cause alterations to microbial composition and alpha diversity in horses $[31,19,50,51,17,52,48,54,55]$ and, interestingly, there was also a much higher variation in the microbial alpha diversity in the Semi-feral group when compared to the Feral and Domesticated group (Additional File 2). Furthermore, the predicted functional analysis for the Semi-feral group included increases in KEGG pathways for cancers, metabolic diseases and immune system diseases, all of which appear to represent an unhealthier phenotype. This may be an indication that a lack of consistency in diet and parasite management on a small holding may be more disruptive to gut microbiota than either a Feral or a Domesticated system with relatively stable management. Indeed, parasite treatment and changes in diet have both been found to be precede GI disease in horses $[16,58,59,60]$.

In contrast to some previous studies comparing wild and domesticated populations [4] the average alpha diversity between groups in this in this study did not differ significantly $(P=0.2)$. Notably, reduced diversity has been associated with domestication and $\mathrm{Gl}$ disease in many species including horses, and based on this data it is tempting to infer that low diversity is a contributing factor in diseases resulting from domestication $[61,62,63,64,65,66]$. However, an increasing body of evidence, including our data, calls this assumption into question, as no significant differences in alpha diversity between equid groups were reported [31,32,33]. Indeed, it may be that a high variation in alpha diversity (as was seen in the Semi-Feral herd), or a sudden drop in alpha diversity within a given population, is a better indication of Gl health than the diversity metric itself.

Overall, taxonomic analysis using a combination of LEfSe and network analysis corroborated the findings of multivariate analyses, demonstrating clear step-wise changes in the abundance of many bacterial taxa between the Domesticated, Semi-Feral and Feral groups (Figs 2,3,4). With respect to the Domesticated group, the taxa Kirimatiellaeota (Kiritimatiellae), Tenericutes (Anaeroplasma,

Page 5/20 
Mycoplasma), Alphaproteobacteria (Rhizobales), Deltproteobacteria (Desulfovibrio), Synergistes (Pyramidobacter), Actinomycetales (Mycobacterium), Negativicutes (Acidaminococcaceae), Optituales and Lentispherae (Victivallaceae) showed a step-wise decrease in relative abundance from Domesticated, to Semi-Feral, to Feral. Of these taxa Kirimatiellaeota, Lentispherae, Alphaproteobacteria and Tenericutes were also negatively correlated with FEC which, given the domesticated group had the lowest FEC, may indicate that high levels of these bacteria were related to low parasite burden. On the other hand, this may actually be a false correlation, since there was a significantly lower FEC in the Domesticated group; indeed, we were not able to find examples of negative relationships between these bacterial taxa and helminth infection in the literature.

Notably, members of the Classes Alpha- and Delta-proteobacteria were significantly higher in the apparently healthy Domesticated ponies. Higher levels of the Class Alphaproteobacteria were largely attributable to increases in the order Rhizobales; whereas an increase in Class Deltaproteobacteria was attributable to an increased abundance of genus Desulfovibrio. In general, elevated levels of Proteobacteria in horses have been linked to increased starch intake $[19,50,67]$. The domesticated group had the highest level of access to ryegrass pasture, which has a higher starch level than rough moorland grasses $[68,69,70]$; therefore, the increase in Proteobacteria seen in the Domesticated group may be linked to dietary starch levels. The long-term effects of concentrate supplementation over the winter may also have contributed to this finding, although there are no studies evaluating the residual effects of starch in horses to confirm this hypothesis. Similar increases in Proteobacteria in horses have also been associated with intestinal inflammation, colic and equine grass sickness [22,71,72,73]. In particular, Weese et al (2015) showed that Proteobacteria increased in horses in the days prior to presenting with colon torsion, suggesting that bacteria belonging to this phylum may play a role in precipitating disease. Therefore, increases in Proteobacteria associated with dietary starch intake, such as seen here, may be a risk factor for the development of GI disease. Other changes in taxa which linked to diet in the Domesticated group included a relative increase in Negativicutes (Acidaminobacteriaceae) abundance. These bacteria use amino-acids as their sole source for growth, and so their increase is consistent with a higher protein diet, consistent with a diet of ryegrass versus rough moorland grasses $[68,69,74]$; furthermore, these findings would explain the functional prediction of increased amino acid metabolism from PICRUST analysis.

In the Domesticated group there were also relative increases in bacterial taxa (e.g. Tenericutes, Synergistes and Actinomycetales) which have been described either in horses, or other species, as pathobionts. For example, the increase in Tenericutes was largely attributable to increases in the abundance of Anaeroplasma and Mycoplasma. These bacteria are gram-negative, anaerobic, and found in mammalian gut microbiota $[75,76]$. They are considered a pathobiont and are known to increase in response to GI inflammation in mice and humans; for example, Mycoplasma are implicated in the aetiology of Chrohn's disease in humans [76,77]. Mycoplasma are also a cause of respiratory disease in horses $[78,79,80]$. The elevated abundance of these taxa may therefore indicate an 'unhealthy' gut microbial profile, however there is currently no data in horses to prove this hypothesis.

With regards to the Feral group, Chlorflexi (Anaerolineaceae), Actinobacteria (Coriobacteriia; Eggerthellaceae) Atopobiaceae, Coriobacteriaceae), Euryarchaeota (Methanobrevibacter) and Clostridiales (Lachnospiracaea, Shuttlesworthia) showed step-wise decreases in abundance from Domesticated > Semi-feral > Feral. Chlorflexi (Anaerolineacae), Actinobacteria (Coriobacteriiia), and Lachnospiraceae (Shuttlesworthia) were also positively correlated with FEC. Coriobacteriales have been found in previous work to increase with helminth infection [80]. Actinobacteria were also increased in helminth infections in cats [82] and mice [83], and they have been shown to increase in response to helminth infection with Trichuris suis infection in pigs alongside dietary inulin supplementation [84]. In the latter case, these changes were linked to an anti-inflammatory Th2 immune response. Hence, it is plausible that some bacteria belonging to these taxa have a genuine link with helminth infection, which may explain their presence at higher levels in the Feral group.

As for the Domesticated group, many of the other taxa which were associated with the Feral group had strong links to diet. In particular, Euryarchaeota (genus Methanobrevibacter) was the bacterial taxa most strongly associated to this group.

Methanobrevibacterspp facilitate the fermentation rate and colonic energy production in the form of SCFA by removing $\mathrm{H} 2 \mathrm{from}$ bacterial fermentation [84], which is important to utilise energy from fibrous diets. High levels of Euryarchaeota are associated with high fibre diets in horses [86,46]; and have also been linked to wild horses in studies comparing wild and domestic populations [32]. Therefore, the association of these taxa with the Feral group in this study most likely reflects the relative high fibre content of the rough moorland diet of the Feral population. Anaerolinaceae are anaerobic fermenters producing methanogens, synergistically linked with members of Euryarcheota [87], such as Methanobrevobacter. Furthermore, Coriobacteriaceae have been shown to increase in abundance proportionately to increasing concentration of cellobiose supplementation in horses [88]. Cellobiose forms when 
cellulose is partially hydrolyzed by the enzyme cellulase [89], suggesting that an increase in these bacteria could be a downstream effect of a high fibre diet. Lachnospiraceae are also associated with the breakdown of cellulose and hemicellulose [90] which may indicate that these bacterial taxa were increased as a result of the high level of fibre in a rough moorland diet. Increased abundance of Lachnospiraceae due to diet may, in turn, have positive health effects for the horse as increased levels of this family have been reported in the faecal microbiome of healthy horses when compared with animals with colitis [22] and diarrhoea [91]. The predicted functional analysis performed in this study supports the role of the microbiota of Feral group in fibre digestion, with KEGG pathway for energy metabolism being significantly increased in the Feral group compared with the other two groups.

\section{Study Limitations}

When considering the observed differences in bacterial taxa between groups we have drawn upon previous literature describing the impact of diet, parasite burden, and handling stress on the equine microbiome; however, given the relatively sparsity of equine microbiome data in general, and the level of variation between studies, it was not always possible to find a clear explanation for our findings. With the inherent limitations of analysing the faecal microbiota in horses [92], our discussion of the potential biological significance of the changes above can only ever be regarded as speculative (mechanistic studies are required to validate the functional hypotheses generated by this work). Furthermore, acknowledging the strong effect of genetics and environment on the microbiome $[93,94,95]$, we can only have confidence that the changes we have observed are true for adult female Exmoor ponies in spring.

\section{Methods}

\section{Animals}

29 adult Exmoor pony mares were sampled from 3 different premises in Somerset and Devon in May 2019. All had a body condition score of between 3 and 4 . Sample group 1 (Feral) was a sub-sample of female adults $(n=10)$ from a wild population $(\sim 50)$ on a 344 acre moorland site (GPS: N51 $19^{\prime} 41.7$ W2 ${ }^{\circ} 45^{\prime} 8.6$ ) which has no human intervention. These animals were either born on this site or transported to it from Exmoor 15 years prior to this study, but all were born wild. This grazing is described as rough, dominated by purple moor grass, brown, bent and deer grass, bracken, heather and many species of native plants. Sample group 2 (Semi-feral) was a sub-sample of female adults $(n=10)$ from a Semi-feral population (approx. 30) on Exmoor (GPS: $\left.51.2142^{\circ} \mathrm{N}, 3.6211^{\circ} \mathrm{W}\right)$. These animals had some human intervention including one anthelmintic treatment of moxidectin in the winter, access to hay in winter and were rotationally grazed on a combination of moorland type land and farmland which was a ryegrass mix. This group were all originally born on Exmoor and removed as youngstock. Sample group 3 (Domesticated) was a sub-sample of females $(n=9)$ from a domesticated and highly managed population (GPS: $50.5627^{\circ} \mathrm{N}, 4.2619^{\circ} \mathrm{W}$ ). These animals were in given anthelmintics 3 times a year, restricted to grazing on ryegrass mix managed paddocks, were often stabled and given concentrate feed and supplementation during the winter, and when deemed necessary. All these ponies were born in captivity. At the time of sampling all individuals were at grass $24 / 7$. None of the animals in the study were known to be pregnant or lactating.

\section{Sample collection and processing}

Freshly voided faecal samples were collected from study participants in May 2019. Fresh samples were immediately snap frozen in liquid nitrogen before storing at $-80^{\circ} \mathrm{C}$ until further processing. A second sub-sample sample was stored anaerobically in a sealable sample bag for faecal egg counting (FEC) and culturing, these samples were stored in a 4-degree fridge and processed within 3 days. FEC were conducted using mini-FLOTAC method, sensitive to 5 eggs per gram $[96,97] .5 \mathrm{~g}$ of faeces was weighed in the mini-FLOTAC, $45 \mathrm{ml}$ of saturated saline (minimum specific gravity of 1.18) was added and then homogenised. Slides were then filled and read to determine eggs per gram value. R studio [43] was used to determine statistical difference between groups by one-way ANOVA $(P=0.005)$.

\section{S rRNA Sequencing}

As replicated by Peachey et al, 2019, Genomic DNA was extracted from individual faecal samples, as well as from three negative 'blank' (= no DNA) controls, using the PowerSoil DNA Isolation Kit (Qiagen, Carlsbad, CA, USA), according to the manufacturers' instructions. The V3-V4 region was PCR-amplified using forward (TACGGGAGGCAGCAG) and reverse primers

(CCAGGGTATCTAATCC). For PCR amplification, the following thermocycling protocol was used: $98 / 2$ min, 20 cycles of $98 / 15$ s, 63

Page $7 / 20$ 
/30 s, and $72 / 30 \mathrm{~s}$, and $725 \mathrm{~min}$. Amplicons were purified using AMPure XP PCR Purification beads (Beckman Coulter, Brea, California, USA). The index PCR was performed using the NEBNext hot start high-fidelity DNA polymerase and Nextera XT index primers (Illumina) according to the following thermocycling protocol: $98 / 30 \mathrm{~s}, 8$ cycles of $98 / 10 \mathrm{~s}, 65 / 75 \mathrm{~s}$ and at $65 / 5 \mathrm{~min}$. The indexed samples were purified using AMPure XP beads and quantified using the Qubit Quant-iTTM dsDNA High-Spec Assay Kit (Life Technologies, Carlsbad, California, USA). Then, equal quantities of DNA from each sample were pooled and the resulting library was quantified using the NEBNextLibrary Quant Kit for Illumina (New England Biolabs Inc). Sequencing was performed on an Illumina MiSeq platform using V3 chemistry (301 bp paired-end reads).

\section{Bioinformatics}

Raw paired-end Illumina reads were processed using the Quantitative Insights Into Microbial Ecology 2 (QIIME2-

2018.4; https://qiime2.org) software suite [98]. Successfully joined sequences were quality filtered (Read cut-off: $17 ; 286$ and $17 ; 255$ for forward and reverse, respectively), dereplicated, chimeras identified, and paired-end reads merged in QIIME2 using DADA2 [99]. A phylogenetic tree was generated for diversity analysis, followed by calculation of alpha and beta diversity metrics using the 'coremetrics-phylogenetic command' in QIIME2. Sequences were assigned to taxonomy using the feature classifier: SILVA 99\% OTUs fulllength sequences. A feature table with the assigned taxonomy was exported from QIIME2 alongside a weighted UniFrac distance matrix for downstream biostatistical analysis. Statistical analyses were executed using the Calypso software [100] (cgenome.net/calypso/); total sum scaling (TSS) normalisation was applied, followed by square route transformation to account for the non-normal distribution of taxonomic counts data. Beta diversity of microbial communities was calculated using weighted UniFrac distances and samples were clustered according to domestication group using principle coordinates analysis (PCoA) and supervised Canonical Correspondence Analysis (CCA). Differences in bacterial alpha diversity (Shannon diversity) between groups were evaluated using an ANOVA. Differences in the relative abundances of individual microbial species between groups were assessed using the Linear Discriminant Analysis Effect Size (LEfSe) workflow [42], by assigning group as the comparison class. Networks of Pearsons correlation were created to identify correlations between bacteria associated with each of the groups. Phylogenetic Investigation of Communities by Reconstruction of Unobserved States (PICRUST) [44] was used to predict the functional pathways associated with the bacterial taxa identified vy 16S rRNA sequencing. LEfSe analysis was used to compare the output of PICRUSt between groups, in the form of KEGG Orthology (KO's) [101]. These data were inputed into a network analysis to demonstrate links between functional pathways associated with the 3 respective groups. Regression analysis between individual bacterial taxa and FEC was performed.

\section{Conclusions}

We have identified clear step-wise changes to the faecal microbiome relative to increasing domestication level of Exmoor ponies. It is important to consider how we can translate these findings into our approach to management of domestic equids. Based on our data, we can suggest faecal biomarkers of a healthy equine microbiome which can potentially be used to assess the $\mathrm{Gl}$ health of equids. For example, adequate levels of Methanobrevibacter could be used as a marker for a "healthy", wildtype microbiome associated with adequate dietary fibre. Specific species of proteobacteria, e.g. Desulfovibrio and Pseudomonas could potentially be used as markers of inflammation, stress or a diet too high in starch. Interestingly, our data also suggest that wide variation in alpha diversity between animals on a premises may be an indication of poor management, leading to 'unstable' microbiomes; which differs from the current thinking that low diversity is associated with poor health. There may be yet more markers which we have identified here; such as increases in Coriobacteriaceae for Feral and Mycoplasma for Domesticated groups. Following on from this study, validation of potential biomarkers within the faecal microbiome should be extended to other systems and breeds of horses, and it is likely that each breed will have its own benchmark for what is considered optimal. We would strongly suggest that people working in this field undertake similar studies in other equine breeds. Nonetheless, we have laid the foundations for a sensible approach to using microbiome data to improve the health of one of the most ancient of domestic animals - the horse.

\section{Abbreviations}

GI- Gastrointestinal

FEC- Feacal egg count 
ENA- European Nucleotide Archive

PCoA- Principle Coordinates Analysis

CCA- Canonical Correspondence Analysis

LEfSE- Linear Discriminant Analysis Effect Size

LTL- Lowest significant taxonomic level

PICRUST- Phylogenetic Investigation of Communities by Reconstruction of Unobserved States

KO- KEGG Orthology

\section{Declarations}

\section{Ethics approval and consent to participate}

This study was approved and carried out in strict accordance and compliance with the guidelines of the Institutional Ethical Review Committee, Department of Veterinary Medicine, University of Bristol. UIN Number: UB/19/025. Written informed consent was obtained from the owner of each of the groups of ponies from which study samples were collected.

\section{Consent for publication}

Not applicable

\section{Availability of data and materials}

All raw sequencing data has been uploaded to ENA with the accession number PRJEB39336.

\section{Competing interests}

The authors declare that they have no competing interests.

\section{Funding}

Not applicable

\section{Authors' contributions}

L.P. and K.B. designed the research; L.P., K.B. and G.D. carried out the research and performed data processing and analyses. K.B. drafted the manuscript text, with input from L.P. The figures were prepared by K.B. and T.J, with input from L.P. The manuscript was reviewed and edited by T.J., K.B. and L.P prior to submission. All authors reviewed and approved the manuscript prior to submission.

\section{Acknowledgements}

We would like to thank the owners of the Exmoor ponies for allowing and facilitating the sampling and the staff and students at the University of Bristol who assisted with the sample collection.

\section{References}

1. Perri A. A wolf in dog's clothing: Initial dog domestication and Pleistocene wolf variation. Journal of Archaeological Science. 2016; 68:1-4.

2. Driscoll CA, Macdonald DW, O'Brien SJ. From wild animals to domestic pets, an evolutionary view of domestication. 2009. PNAS: 106: 9971-9978.

3. Zeder MA. Core questions in domestication research. Proceedings of the National Academy of Sciences. 2016; 112: $3191-3198$. 
4. Metcalf JL, Song SJ, Morton JT., Weiss S, Seguin-Orlando A, Joly F, et al. Evaluating the impact of domestication and captivity on the horse gut microbiome. Scientific Reports. 2017; 7:15497

5. McKenzie VJ, Song S J, Delsuc F, Prest TL, Oliverio A M, Korpita TM, et al. 2017. The Effects of Captivity on the Mammalian Gut Microbiome, Integrative and Comparative Biology. 2017; 57:690-704

6. Cubas ZS. Special challenges of maintaining wild animals in captivity in South America. Revue scientifique et technique (International Office of Epizootics). 1996;15:267-287.

7. Fowler ME. An overview of wildlife husbandry and diseases in captivity. Revue scientifique et technique (International Office of Epizootics). 1996; 15:15-42.

8. Mason GJ. Species differences in responses to captivity: stress, welfare and the comparative method. Trends Ecol Evol. 2010; 25:713-721.

9. le Roex N, Paxton M, Adendorff J, Ferreira S, O'Riain MJ. Starting small: long-term consequences in a managed large-mammal population. Zool. 2018; 306: 95-100.

10. Clauss M, Keller A, Peemöller A, Nygrén K, Hatt JM, Nuss K. Postmortal radiographic diagnosis of laminitis in a captive European moose (Alces alces). Schweiz Arch Tierheilkd. 2009; 151:545-549.

11. Schilcher B, Baumgartner K, Geyer H, Liesegang A. Investigations on rumen health of different wild ruminants in relation to feeding management. J Zoo Aquar Res. 2013; 1:28-30

12. Whitehouse-Tedd KM, Lefebvre SL, \& Janssens GP. Dietary factors associated with faecal consistency and other indicators of gastrointestinal health in the captive cheetah (Acinonyx jubatus). PloS one. 2015; 10:e0120903.

13. Bell RJW, Mogg TD, Kingston JK. Equine gastric ulcer syndrome in adult horses: A review. N Z Vet J. 2007; 55:1

14. Hart S \& Southwood LL. The enigma of post operative recurrent colic: Challenges with diagnosis and management. Equine Vet. J. $2010 ; 2: 408-411$

15. Scantlebury CE, Archer, DC, Proudman CJ \& Pinchbeck GL. Recurrent colic in the horse: Incidence and risk factors for recurrence in the general practice population. Equine Vet. J. 2011; 43: 81-88.

16. Curtis L, Burford JH, England GCW, Freeman SL. Risk factors for acute abdominal pain (colic) in the adult horse: A scoping review of risk factors, and a systematic review of the effect of management-related changes. PLOS ONE. 2019; 14: e0219307

17. Shepherd ML, Swecker WS, Jensen RV, Ponder MA. Characterization of the fecal bacteria communities of forage-fed horses by pyrosequencing of 16S rRNA V4 gene amplicons. FEMS Microbial. 2012; 326: 6-68

18. Daly K, Proudman CJ, Duncan SH, Flint HJ, Dyer J, Shirazi-Beechey SP. Alterations in microbiota and fermentation products in equine large intestine in response to dietary variation and intestinal disease. Br. J. Nutr. 2012; 107:989-995

19. Bulmer LS, Murray JA, Burns NM, Garber A; Wemelsfelder F; McEwan NR, Hastie PM. High-starch diets alter equine faecal microbiota and increase behavioural reactivity. Rep. 2019; 9:18621.

20. Lindenberg F, Krych L, Kot W, Fielden J, Frøkiær H, van Galen G, et al. Development of the equine gut microbiota. Sci. Rep. 2019; 9:14427

21. Costa MC, Silva G, Ramos RV, Staempfli HR, Arroyo LG, Kim P, Weese JS. Characterization and comparison of the bacterial microbiota in different gastrointestinal tract compartments in horses. Vet. J. 2015; 205:74-80.

22. Costa MC, Arroyo LG, Allen-Vercoe E, Stampfli HR, Kim PT, Sturgeon A, Weese JS. Comparison of the fecal microbiota of healthy horses and horses with colitis by high throughput sequencing of the V3-V5 region of the 16S rRNA gene. PLoS One. 2012; 7:e41484.

23. Salem SE, Maddox TW, Antczak P, Ketley JM, Williams NJ, Archer DC. Acute changes in the colonic microbiota are associated with large intestinal forms of surgical colic. BMC Vet Res. 2019; 15: 468.

24. Elzinga SE, Weese JS \& Adams AA. Comparison of the fecal microbiota in horses with equine metabolic syndrome and metabolically normal controls fed a similar all-forage diet. J. Equine Vet. Sci. 2016; 44: 9-16.

25. Morrison PK, Newbold CL, Jones E, Worgan HJ, Grove-White D, Dugdale AH, et al. The Equine Gastrointestinal Microbiome: Impacts of Age and Obesity. Front. Microbiol. 2018: 9:3017.

26. Morrison PK, Newbold CJ, Jones E, Worgan HJ, Grove-White DH, Dugdale AH, et al. The equine gastrointestinal microbiome: impacts of weight-loss. BMC Vet Res. 2020; $16: 78$

Page $10 / 20$ 
27. Schmidt E, Mykytczuk N \& Schulte-Hostedde Al. Effects of the captive and wild environment on diversity of the gut microbiome of deer mice (Peromyscus maniculatus). ISME J. 2019; 13:1293-1305.

28. Clayton JB, Vangay P, Huang H, Ward T, Hillmann BM, Al-Ghalith GA, et al. Captivity humanizes the primate microbiome. Proc. Natl. Acad. Sci. 2016; 113, 10376-10381.

29. Wasimuddin, Menke S, Melzheimer J, Thalwitzer S, Heinrich S, Wachter B, Sommer S. Gut microbiomes of free-ranging and captive Namibian cheetahs: diversity, putative functions, and occurrence of potential pathogens. Mol Ecol. 2017; 26: 5515-5527

30. Gibson KM, Nguyen BN, Neumann LM, Miller M, Buss P, Daniels S, Ahn MJ, Crandall KA, Pukazhenthi B. Gut microbiome differences between wild and captive black rhinoceros - implications for rhino health. Sci Rep. 2019; 9: 7570.

31. Li Y, Zhang K, Liu Y, Li K, Hu D, Wronski T. Community Composition and Diversity of Intestinal Microbiota in Captive and Reintroduced Przewalski's Horse (Equus ferus przewalskii). Microbiol. 2019; 10:1821

32. Zhao Y, Li B, Bai D, Huang J, Shiraigo W, Yang L, et al. Comparison of Fecal Microbiota of Mongolian and Thoroughbred Horses by High-throughput Sequencing of the V4 Region of the 16S rRNA Gene. AJAS. 2016; 29:1345-1352.

33. Tang L, Li Y, Srivathsan A, Gao Y, Li K, Hu D, Zhang D. Gut Microbiomes of Endangered Przewalski's Horse Populations in Shortand Long-Term Captivity: Implication for Species Reintroduction Based on the Soft-Release Strategy. Front Microbiol. 2020; 11: 363.

34. Hall A, Tolonen A, Xavier R. Human genetic variation and the gut microbiome in disease. Nat Rev Genet. 2017; 18: 690-699.

35. Haro C, Rangel-Zúñiga O A, Alcalá-Díaz JF, Gómez-Delgado F, Pérez-Martínez P, Delgado-Lista J, et al. Intestinal Microbiota Is Influenced by Gender and Body Mass Index. PloS one. 2016; 1: e0154090.

36. Org E, Mehrabian M, Parks BW, Shipkova P, Liu X, Drake TA, Lusis AJ. Sex differences and hormonal effects on gut microbiota composition in mice. Gut microbes. 2016; 7: 313-322

37. Markle JG, Frank DN, Mortin-Toth S, Robertson C E, Feazel LM, Rolle-Kampczyk U, et al. Sex differences in the gut microbiome drive hormone-dependent regulation of autoimmunity. 2013. Science (New York, N.Y.). 339: 1084-1088

38. Mueller S, Saunier K, Hanisch C, Norin E, Alm L, Midtvedt T, et al. Differences in fecal microbiota in different European study populations in relation to age, gender, and country: a cross-sectional study. Applied and environmental microbiology. 2006; 72 : 1027-1033.

39. Singh P and Manning SD. Impact of age and sex on the composition and abundance of the intestinal microbiota in individuals with and without enteric infections. Ann Epidemiol. 2016; 26:380-385.

40. Prabhu VR, Wasimuddin, Kamalakkannan R, Arjun M S, Nagarajan M. Consequences of Domestication on Gut Microbiome: A Comparative Study Between Wild Gaur and Domestic Mithun. Front Microbiol. 2020; 11: 133.

41. Quast C, Pruesse E, Yilmaz P, Gerken J, Schweer T, Yarza P, Peplies J, Glöckner FO(2013) The SILVA ribosomal RNA gene database project: improved data processing and web-based tools. 2013; Nucleic Acids Res. 41: D590-D596.

42. Segata N, Izard J, Waldron L, Gevers D, Miropolsky L, Garrett WS. 2011. Metagenomic biomarker discovery and explanation. Genome Biol. 2011; 12: R60

43. RStudio Team (2020). RStudio: Integrated Development for R. RStudio, PBC, Boston, MA URLhttp://www.rstudio.com/.

44. Langille MG, Zaneveld J, Caporaso JG, McDonald D, Knights D, Reyes J A, et al. Predictive functional profiling of microbial communities using 16S rRNA marker gene sequences. Biotechnol. 2013; 31 814-821

45. Venable EB, Bland SD, McPherson JL, Francis J. Role of the gut microbiota in equine health and disease. Animal Frontiers. 2016; 6:3.

46. O'Donnell IMM, Harris HM, Jeffery IB, Claesson MJ, Younge B, O'Toole PW, Ross RP. The core faecal bacterial microbiome of Irish Thoroughbred racehorses. Lett. Appl. Microbiol. 2013; 57:492-501.

47. Proudman CJ, Hunter JO, Darby AC, Escalona EE, Batty C, Turner C. Characterisation of the faecal metabolome and microbiome of Thoroughbred racehorses. Equine Vet. J. 2015; 47:580-586.

48. Peachey LE, Molena R A, Jenkins TP, Di Cesare A, Traversa D, Hodgkinson JE, Cantacessia C. The relationships between faecal egg counts and gut microbial composition in UK Thoroughbreds infected by cyathostomins. Int J Parasitol. 2018; 48: 403-412

49. Garber A, Hastie P, Murray J. Factors Influencing Equine Gut Microbiota: Current Knowledge. J. Equine Vet. Sci. 2020; 88:102943

50. Dougal K, de la Fuente G, Harris PA, Girdwood SE, Pinloche E, Geor RJ, et al. Characterisation of the faecal bacterial community in adult and elderly horses fed a high fibre, high oil or high starch diet using 454 pyrosequencing. PLoS One. 2014; 9:e87424.

Page 11/20 
51. Respondek F, Goachet AG \& Julliand V. Effects of dietary short-chain fructooligosaccharides on the intestinal microflora of horses subjected to a sudden change in diet. J. Anim. Sci. 2018; 86: 316-323.

52. Willing B, Vörös A, Roos S, Jones C, Jansson A, Lindberg JE. Changes in faecal bacteria associated with concentrate and forageonly diets fed to horses in training. Equine Vet. J. 2009; 41: 908-914.

53. Costa MC, Stämpfli HR, Arroyo LG, Vercoe EA, Gomes RG, Weese J.S. Changes in the equine fecal microbiota associated with the use of systemic antimicrobial drugs. BMC Vet. Res. 2015; 11:19

54. Peachey LE, Castro C, Molena RA, Jenkins TP, Griffin JL, Cantacessi C. Dysbiosis associated with acute helminth infections in herbivorous youngstock - observations and implications. Rep. 2019; 9:11121.

55. Walshe N, Duggan V, Cabrera-Rubio R, Crispie F, Cotter P, Feehan O, Mulcahy G. Removal of adult cyathostomins alters faecal microbiota and promotes an inflammatory phenotype in horses. J. Parasitol. 2019; 6:489-500

56. Mach N, Ruet A, Clark A, Bars-Cortina D, Ramayo-Caldas Y, Crisci E, et al. Priming for welfare: gut microbiota is associated with equitation conditions and behavior in horse athletes. Sci Rep. 2020. 10: 8311.

57. Daniels S, Leng J, Ellis R, Swann J, Moore-Colyer M, Proudman C. The Effect of Moxidectin Treatment on the Equine Hind Gut Microbiome, Metabonome and Feed Fermentation Kinetics in Horses with Very Low Parasite Burdens. Equine Veterinary Education. 2017; 29:58.

58. Marr C. On the question of colic: are answers beginning to emerge? Equine Vet. J. 2012; 44:384-6.

59. Cohen ND, Gibbs PG, Woods AM. Dietary and other management factors associated with colic in horses. J. Am. Vet. 1999; 215: 53-60.

60. Uhlinger C. Effects of three anthelmintic schedules on the incidence of colic in horses. Vet. J. 1990; 22: 251-254.

61. Manichanh C, Rigottier-Gois L, Bonnaud E, Gloux K, Pelletier E, Frangeul L, et al. 2006. Reduced diversity of faecal microbiota in Crohn's disease revealed by a metagenomic approach. Gut. 2006; 55:205-211.

62. Ismail IH, Oppedisano F, Joseph SJ, Boyle RJ, Licciardi PV, Robins-Browne RM, Tang ML. Reduced gut microbial diversity in early life is associated with later development of eczema but not atopy in high-risk infants. Pediat Allergy Immunol. 2012; 23: 674681.

63. Abrahamsson TR, Jakobsson HE, Andersson AF, Björkstén B, Engstrand L, Jenmalm MC. Clin. Exp. Allergy. 2014; 44:842- 850.

64. Nylund L, Nermes M, Isolauri E, Salminen S, de Vos WM, Satokari R. Severity of atopic disease inversely correlates with intestinal microbiota diversity and butyrate-producing bacteria. Allergy. 2015; 70: 241- 244.

65. Giloteaux L, Goodrich JK, Walters WA, Levine SM, Ley RE, Hanson MR. Reduced diversity and altered composition of the gut microbiome in individuals with myalgic encephalomyelitis/chronic fatigue syndrome. Microbiome. 2016; 4:30.

66. Stewart HL, Southwood LL, Indugu N, Vecchiarelli B, Engiles JB, Pitta D. Differences in the equine faecal microbiota between horses presenting to a tertiary referral hospital for colic compared with an elective surgical procedure. Vet. J. 2019; 51:336-342.

67. Hansen NCK, Avershina E, Mydland LT, Næsset JA, Austbø D, Moen B, Måge I, Rudi K. High nutrient availability reduces the diversity and stability of the equine caecal microbiota. Microb Ecol Health and Dis. 2015; 26:1.

68. Rivero JM, Balocchi OA, Moscoso Cj, Siebaldn JA, Neumann FB, Meyer DM, Lee MRF. Does the "high sugar" trait of perennial ryegrass cultivars express under temperate climate conditions?. Grass Forage Sci. 2019; 74:496-508.

69. Miller GR, Miles J, Heal OW. Moorland Management: A study of Exmoor. Institute of Terrestrial Ecology. 1984. http://nora.nerc.ac.uk/id/eprint/5145/1/Moorland_Exmoor.pdf

70. Francis SA, Chapman DF, Doyle PT, Leury BJ, Egan AR. Non- Structural carbohydrate content of a perennial ryegrass cultivar bred for high sugar levels, compared to 'normal' perennial ryegrass and white clover. Prod. Aust. 202; 24:73-76.

71. Weese JS, Holcombe SJ, Embertson RM, Kurtz KA, Roessner HA, Jalalim M, et al. Changes in the faecal microbiota of mares precede the development of post partum colic. Equine Vet J. 2015; 47:641-9.

72. Leng J, Proudman C, Blow F, Darby A, Swann J. Understanding Intestinal Microbiota in Equine Grass Sickness: Next Generation Sequencing of Faecal Bacterial DNA. Clinical Research Abstracts of the British Equine Veterinary Association Congress. 2015; 47:48

73. Leng J, Proudman C, Darby A, Blow F, Townsend N, Miller A, Swann, J. 2018. Exploration of the Fecal Microbiota and Biomarker Discovery in Equine Grass Sickness. J. Proteome Res. 2018; 17: 1120-1128.

Page $12 / 20$ 
74. Halling MA, Longland AC, Martens S, Nesheim L, O'Kiely P. Accumulation of water soluble carbohydrates in two perennial ryegrass cultivars at nine European sites. In: Luscher A, Jeangros B, Kessler W, Huguenin O, Lobsiger M, Millar N. Suter D, editors. Land use systems in grassland dominated regions. Proceedings of the 20th general meeting of the European grassland federation, Luzern, Switzerland; 2004. p. 954-956.

75. Suau A, Bonnet R, Sutren M, Godon JJ, Gibson GR, Collins MD, Doré J. Direct analysis of genes encoding 16S rRNA from complex communities reveals many novel molecular species within the human gut. Appl Environ Microbiol. 1999; 65:4799-807.

76. Roediger W. Intestinal Mycoplasma in Crohn's Disease. Novartis Foundation symposium. 2004; 263: 85-93.

77. Roediger W, Cummins A, Burke J, Philpot R. Mycoplasma fermentans in acute Crohn's disease: a putative aetio-pathogenic agent Inflamm. Bowel Dis. 2011; 17:59.

78. Antal T, Szabó I, Antal V, Vajda G, Polner A, Totth B, et al. Respiratory disease of horses associated with Mycoplasma infection. Zentralblatt fur Veterinarmedizin. Reihe B. J. Vet. Med. 1988; 35: 264-270.

79. Wood JLN, Chanter N, Newton JR, Burrell MH, Dugdale D, Windsor HM, et al. An outbreak of respiratory disease in horses associated with Mycoplasma felis infection. Veterinary Record. 1997; 140: 388-391.

80. Carman S, Rosendal S, Huber L, Gyles C, McKee S, Willoughby RA, et al. Infectious agents in acute respiratory disease in horses in Ontario. Vet. Diag. invest. 1997; 9: 17-23.

81. Jenkins TP, Peachey LE, Ajami NJ, MacDonald AS, Hsieh MH, Brindley PJ, et al. Schistosoma mansoni infection is associated with quantitative and qualitative modifications of the mammalian intestinal microbiota. Sci. Rep. 2018; 8: 12072.

82. Duarte Am, Jenkins TP, Latrofa MS, Giannelli A, Papadopoulos E, Madeira de Carvalho L, et al. Helminth infections and gut microbiota a feline perspective. Parasit. Vectors. 2016; 9: 625.

83. Fricke WF, Song Y, Wang AJ, Smith A, Grinchuk V, Mongodin E, et al. Type 2 immunity-dependent reduction of segmented filamentous bacteria in mice infected with the helminthic parasite Nippostrongylus brasiliensis. Microbiome. 2015; 3: 40.

84. Myhill LJ, Stolzenbach S, Hansen T, Skovgaard K, Stensvold CR, Andersen LO, et al. Mucosal Barrier and Th2 Immune Responses Are Enhanced by Dietary Inulin in Pigs Infected With Trichuris suis. Front. Immunol. 2018; 9: 2557.

85. Shin NR, Whon TW, Bae JW. Proteobacteria: microbial signature of dysbiosis in gut microbiota. 2015. Trends in Biotechnology. 33:496-503.

86. Fernandes KA, Kittelmann S, Rogers CW, Gee EK, Bolwell CF, Bermingham EN, Thomas DG. Faecal microbiota of forage-fed horses in New Zealand and the population dynamics of microbial communities following dietary change. PLoS One. 2014; 9:e112846.

87. Mcllroy SJ, Kirkegaard R H, Dueholm MS, Fernando E, Karst SM, Albertsen M, Nielsen PH. Culture-Independent Analyses Reveal Novel Anaerolineaceae as Abundant Primary Fermenters in Anaerobic Digesters Treating Waste Activated Sludge. Front. Microbiol. 2017; 8: 1134.

88. Paßlack N, Vahjen W, Zentek J. Impact of Dietary Cellobiose on the Fecal Microbiota of Horses. J. Equine Vet. Sci. 2020; 91: 103106.

89. Ouellette R and Rawn D. Principles of Organic Chemistry. $1^{\text {st }}$ Elsevier; 2015.

90. Biddle A, Stewart L, Blanchard J, Leschine S. Untangling the genetic basis of fibrolytic specialization by Lachnospiraceae and Ruminococcaceae in diverse gut communities. Diversity; 2013. 5: 627-640.

91. Schoster A, Staempfli HR, Guardabassi LG, Jalali M, Weese JS. Comparison of the fecal bacterial microbiota of healthy and diarrheic foals at two and four weeks of life. BMC Vet Res. 2017; 13:144.

92. Kauter A, Epping L, Semmler T, Antao E, Kannapin D, Stoeckle SD, et al. The gut microbiome of horses: current research on equine enteral microbiota and future perspectives. anim microbiome. 2019; 1: 14.

93. Bonder M, Kurilshikov A, Tigchelaar E, Mujagic Z, Imhann F, Arnau VV, et al. The effect of host genetics on the gut microbiome. Nat Genet. 2016; 48:1407-1412.

94. Lim MY, You HJ, Yoon HS, Kwon B, Lee JY, Lee S, et al. The effect of heritability and host genetics on the gut microbiota and metabolic syndrome. Gut. 2017; 66:1031-1038.

95. Phillips ML. Gut reaction: environmental effects on the human microbiota. Environ Health Perspect. 2009; 117:A198-A205.

96. Cringoli G, Maurelli MP, Levecke B, Bosco A, Vercruysse J, Utzinger J, Rinaldi L. The Mini-FLOTAC technique for the diagnosis of helminth and protozoan infections in humans and animals. Nat. Protoc. 2017; 12:1723-1732. 
97. Bosco A, Rinaldi L, Maurelli MP, Musella V, Coles GC, Cringoli G. The comparison of FLOTAC, FECPAK and McMaster techniques for nematode egg counts in cattle. Acta Parasitologica. 2014; 59:625-

98. Caporaso J, Kuczynski J, Stombaugh J, et al.QIIME allows analysis of high-throughput community sequencing data. Nat Methods. 2010; 7: 335-336.

99. Callahan BJ, McMurdie PJ, Rosen MJ, Han AW, Johnson AJ, Holmes SP. DADA2: High-resolution sample inference from Illumina amplicon data. Nat Methods. 2016; 13: 581-583.

100. Zakrzewski M, Proietti C, Ellis JJ, Hasan S, Brion MJ, Berger B, Krause L. Calypso: a user-friendly web-server for mining and visualizing microbiome-environment interactions. Bioinformatics (Oxford, England). 2017; 33: $782-783$.

101. Kanehisa M, Goto S. KEGG: kyoto encyclopedia of genes and genomes. Nucleic Acids Res. $2000 ; 28: 27-30$.

\section{Tables}

Table 1: Bacterial taxa with a significantly different relative abundance between Domesticated, Semi-feral and Feral groups according to LEfSe analysis; and those correlated with faecal egg count (FEC) in regression analysis. Rows under group headings are highlighted grey when the taxa was relatively increased in that group. For FEC, rows highlighted green represent a positive correlation with FEC, and those highlighted red represent a negative correlation (n.b. only those taxa which changed in a step-wise modus from Domesticated to Semi-Feral to Feral are shown here; for full LEfSe results see Additional Table 1).

\section{Table 1}




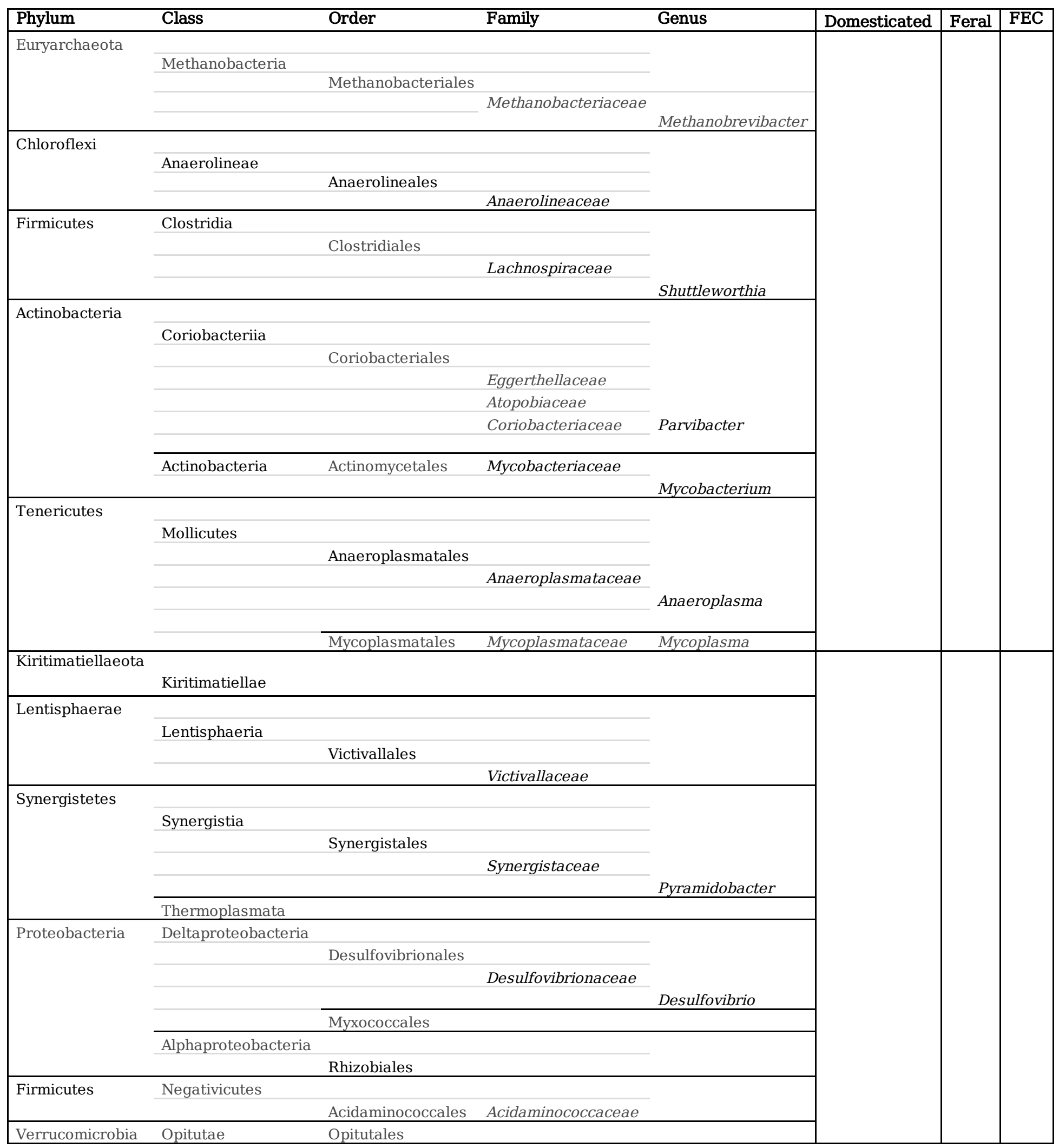

\section{Figures}




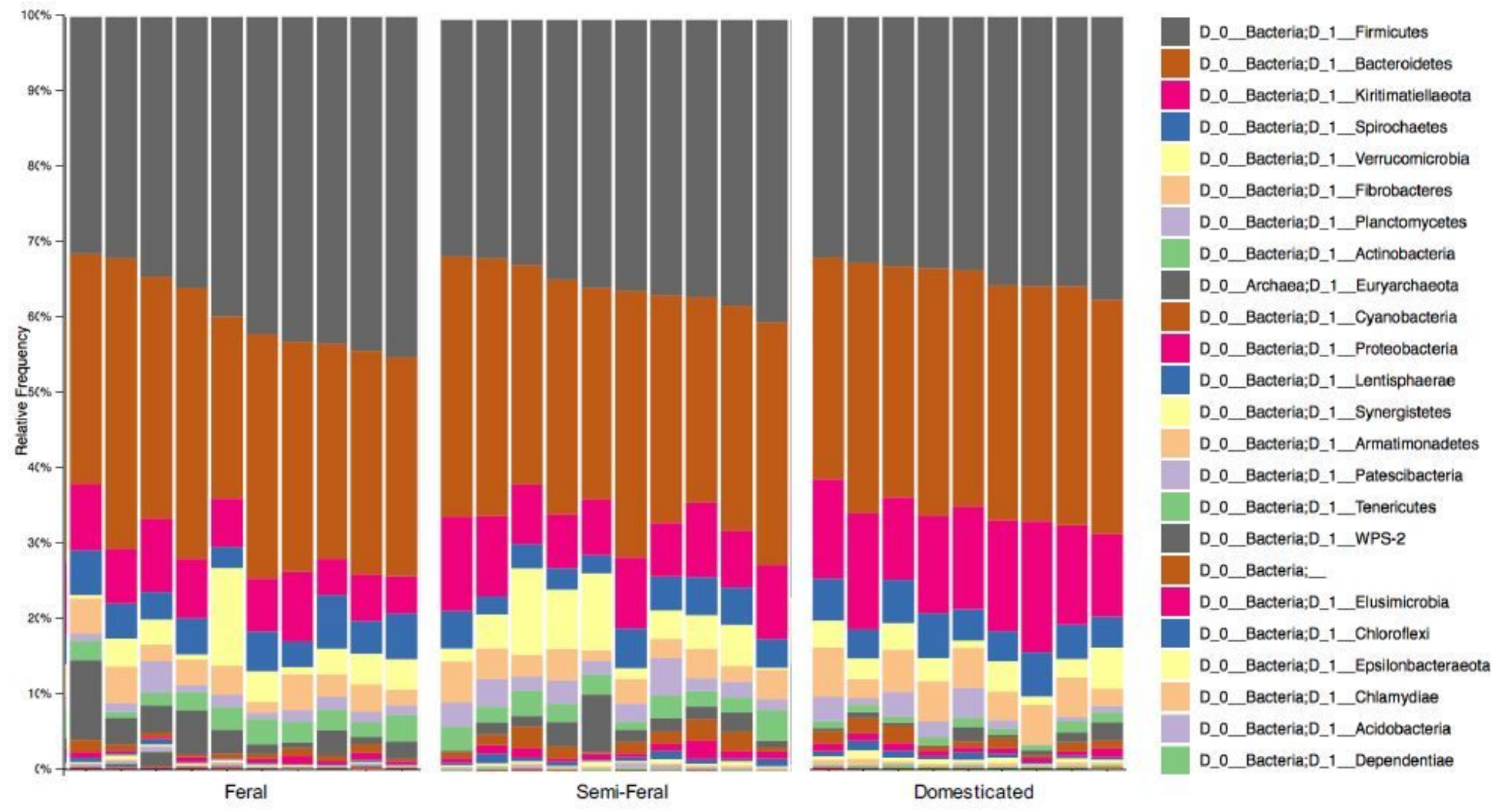

Figure 1

Bar charts depicting the relative abundances of faecal bacterial phyla of the Feral, Semi-Feral and Domesticated Exmoor pony groups.

(a)

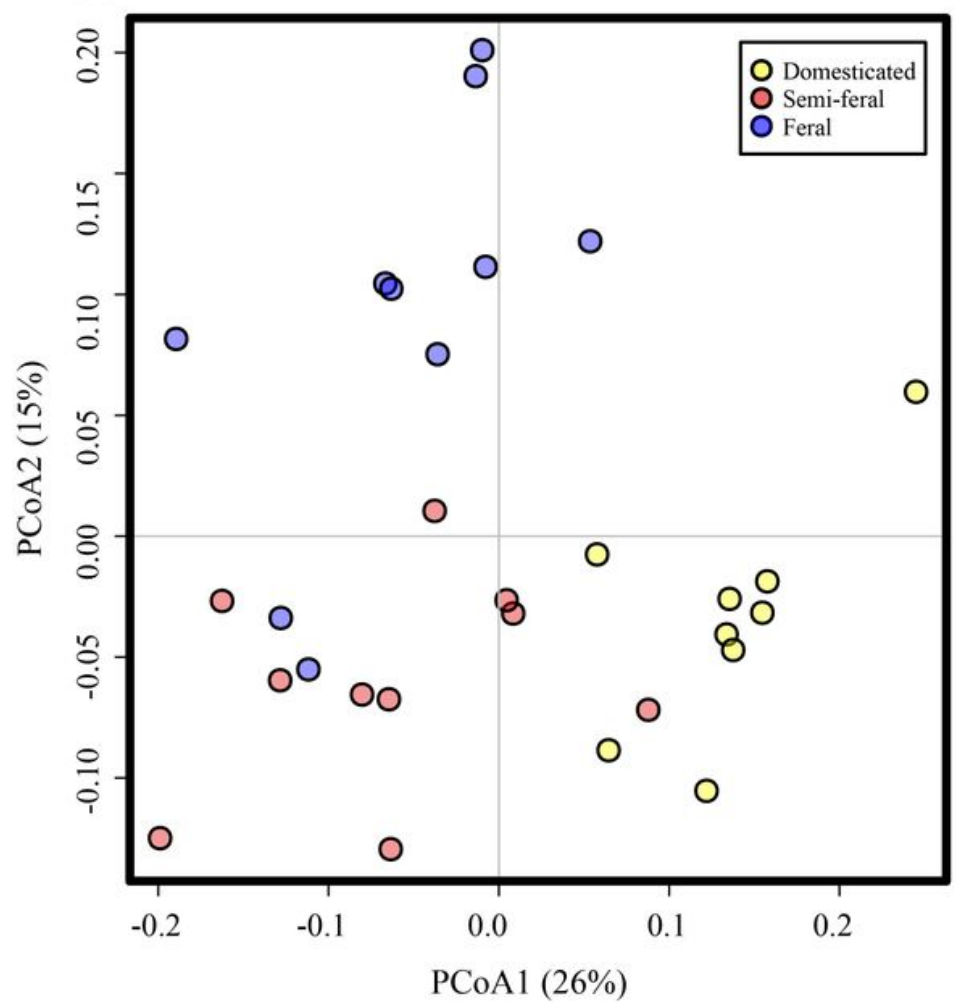

(b)

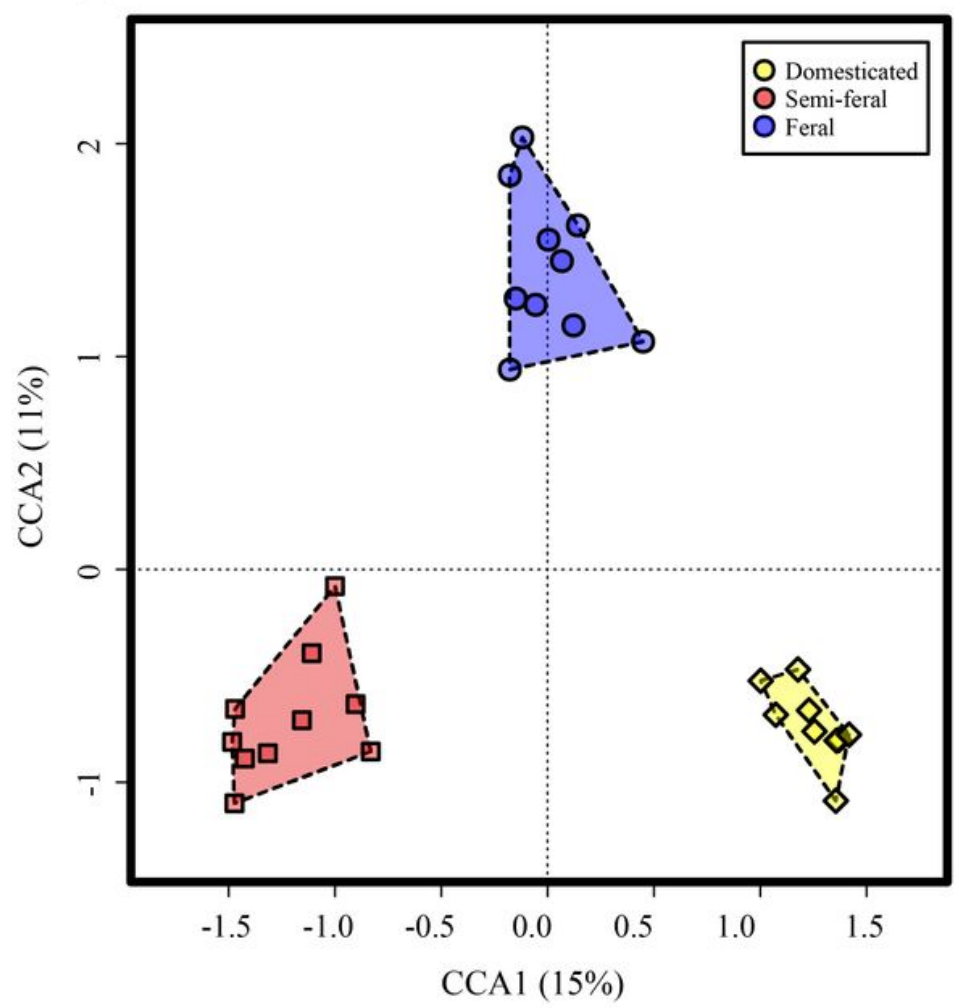

Figure 2 
Multivariate analysis of weighted unifrac distance beta diversity measures between samples from Feral, Semi-feral and Domesticated Exmoor groups showed clear clustering according to domestication level. (a) Unsupervised Principle Coordinates Analysis (PCoA) plots comparing the faecal microbial beta diversity of Domesticated, Semi-feral and Feral groups. (b) The faecal microbial beta diversity of faecal samples ordered by Domesticated, Semi-feral and Feral groups using supervised Canonical Correspondence Analysis (CCA) ( $P=0.001)$.
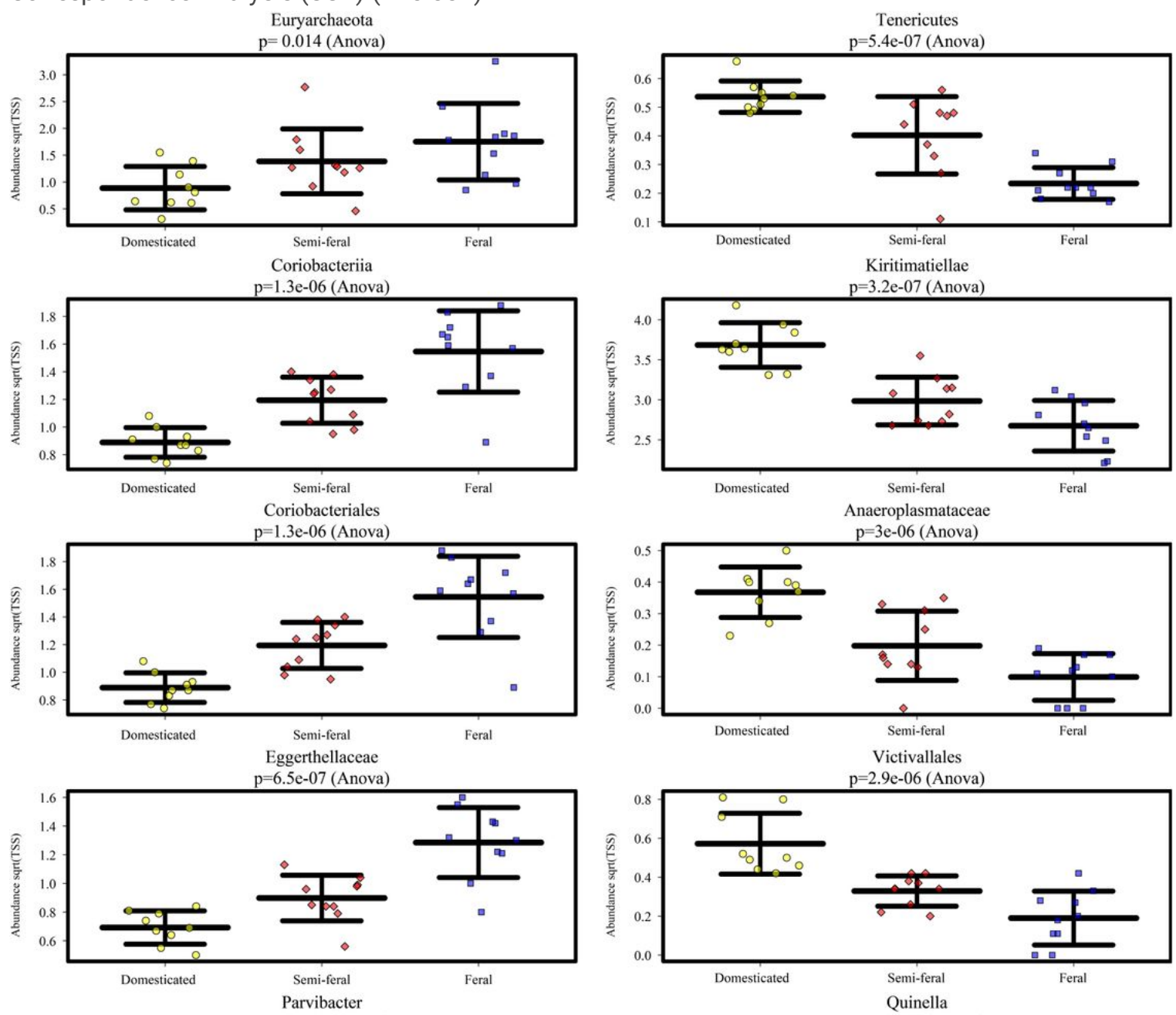

$\mathrm{p}=9.3 \mathrm{e}-06($ Anova)
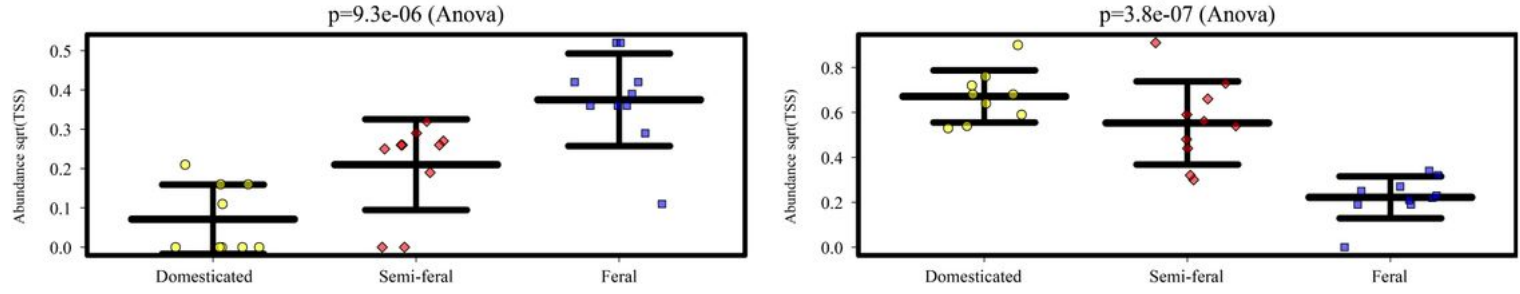

Figure 3

Examples of bacterial taxa showing significant step-wise changes in relative abundance between Domesticated, Semi-Feral and Feral group at each taxonomic level. Represented by ANOVA plots (those which were most statistically significant were selected for presentation). 


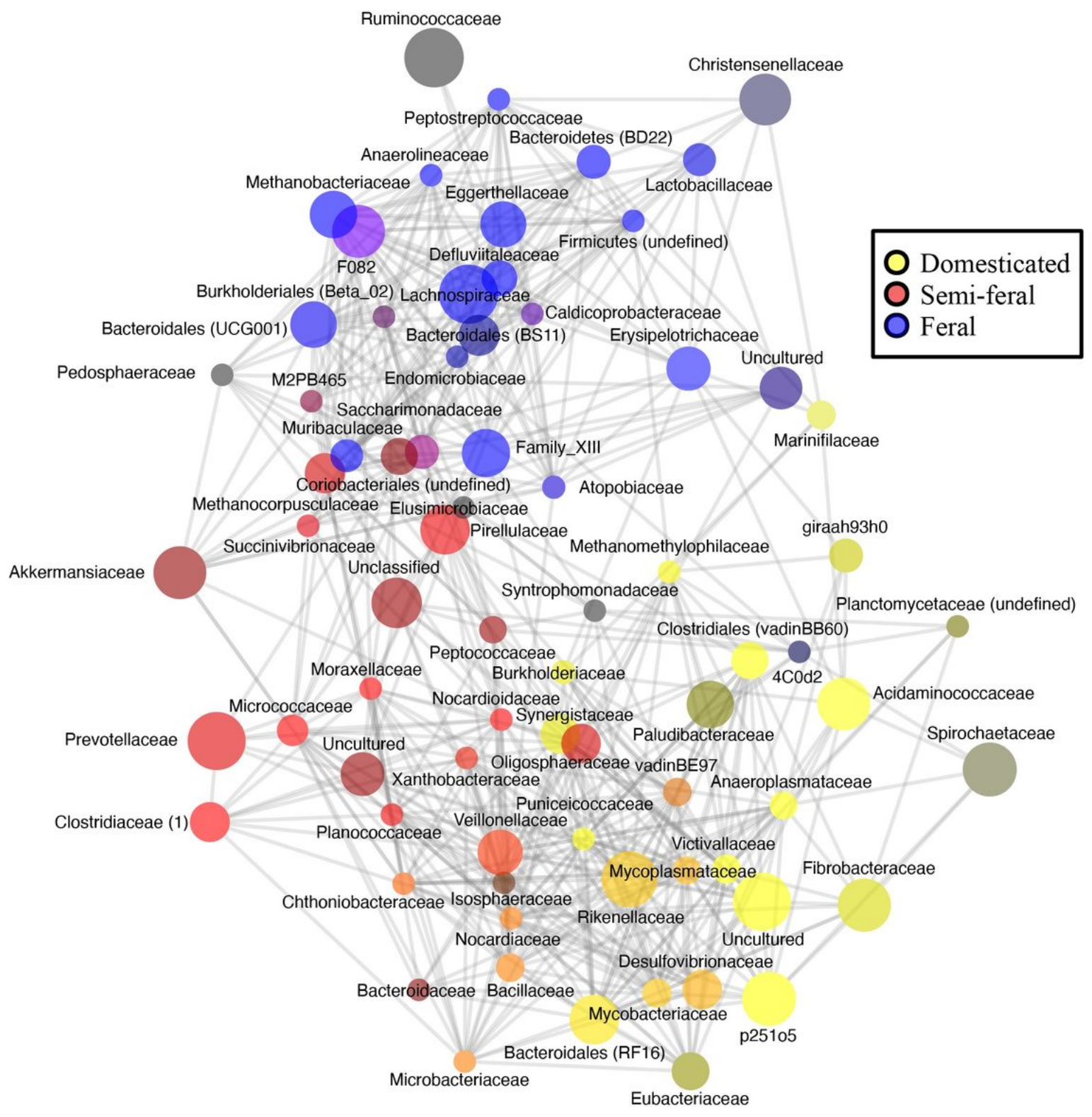

Figure 4

Network analysis with Pearson Correlation at Family level. Showing correlations between bacterial families and their relative association with Domesticated, Semi-feral and Feral groups. 

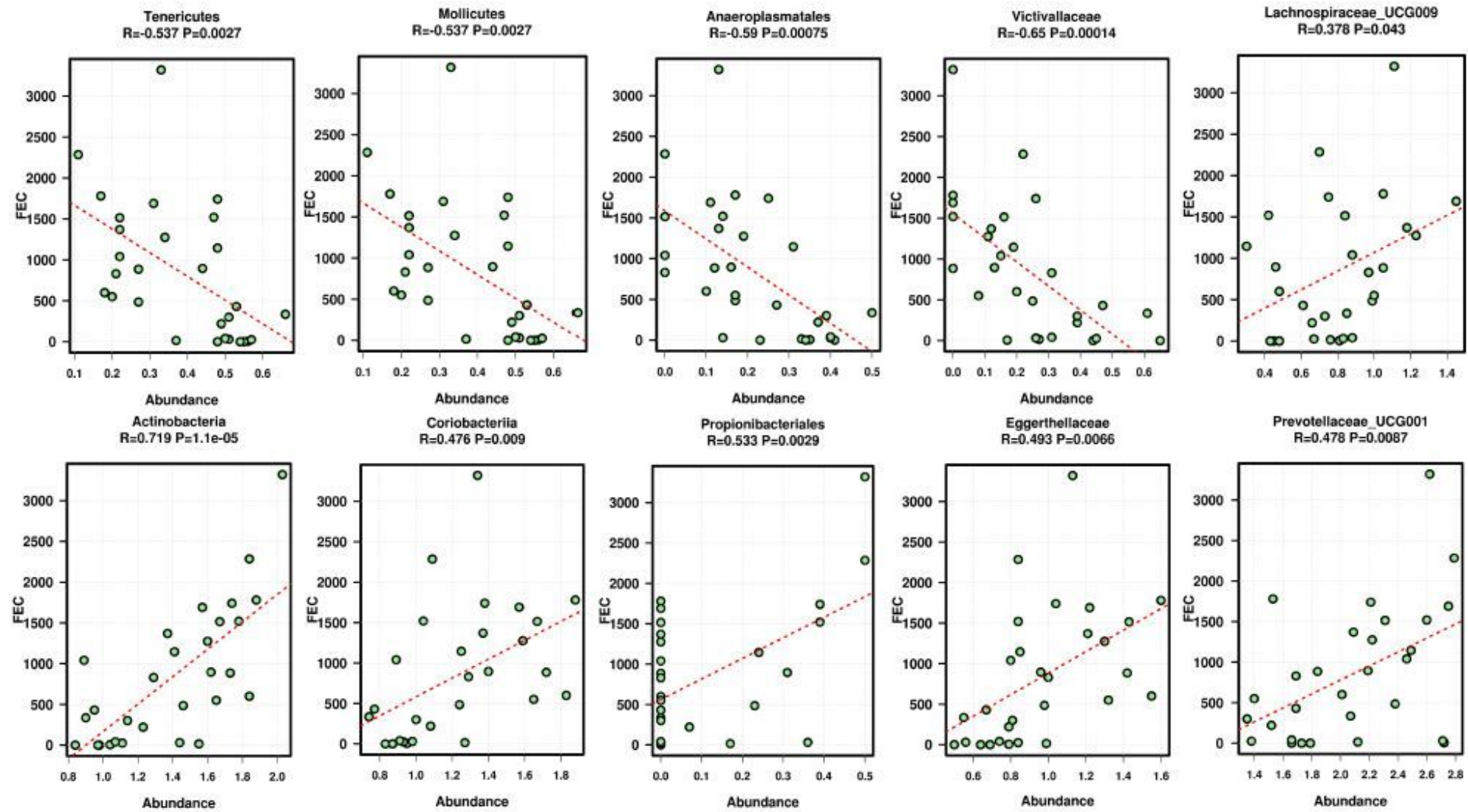

Figure 5

Regression plots showing examples of bacteria which were positively or negatively associated with faecal egg count across all groups. The examples selected were the most statistically significant at each taxonomic level. 


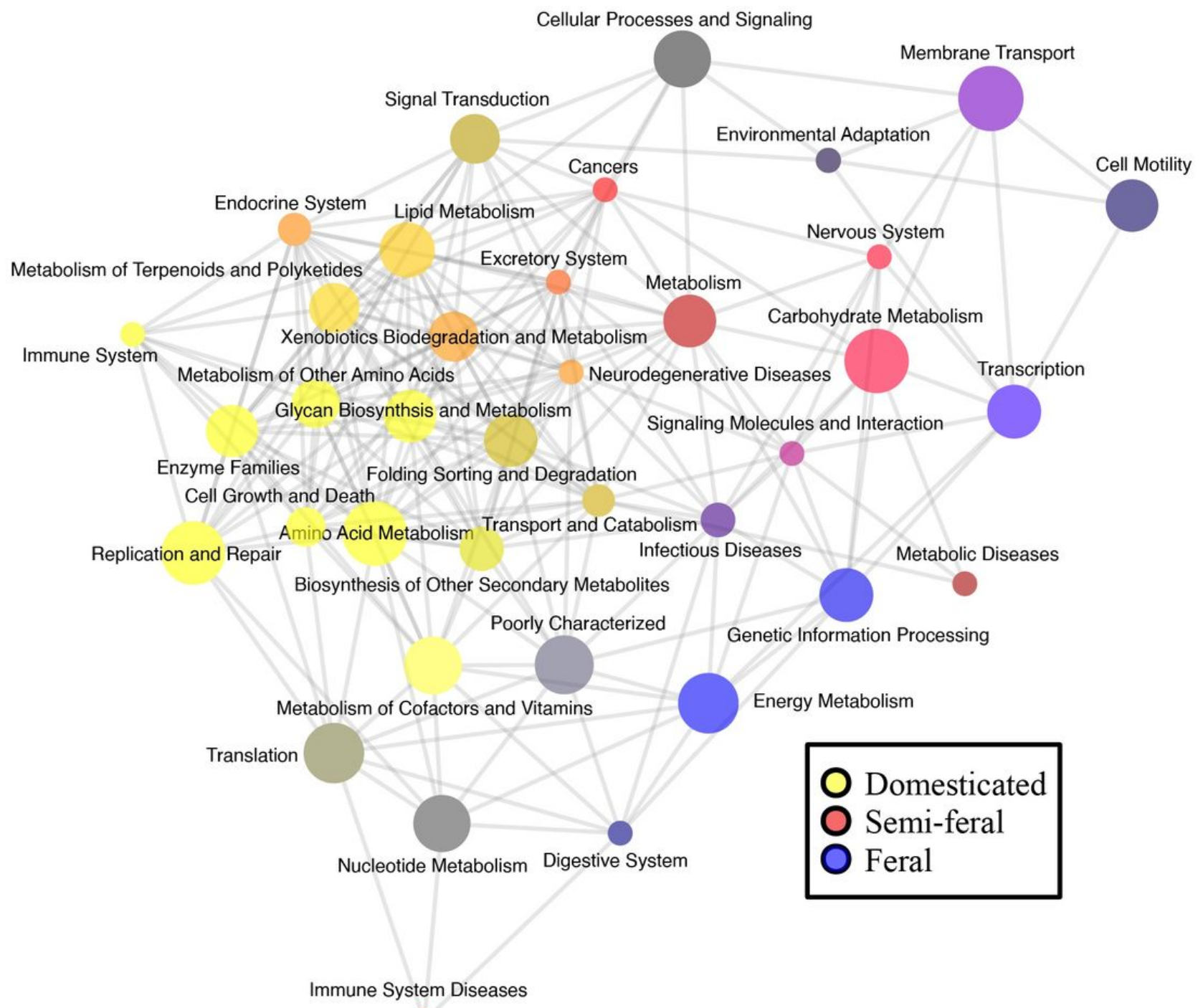

Figure 6

Network analysis with Pearson Correlation of predicted functional pathways at Kegg level 2 based on taxonomic data. Showing correlations between metabolic pathways, and their relative association with the Feral, Semi-feral and Domesticated groups.

\section{Supplementary Files}

This is a list of supplementary files associated with this preprint. Click to download.

- AdditionalFile1.png

- AdditionalFile2.png

- AdditionalFile3.png

- AdditionalFile4.png

- AdditionalTable1.xlsx

- AdditionalTable2.csv 